\title{
AL-AZHAR
}

The Official Publication of The

Assiut Dental Journal

Faculty of Dental medicine.

Al-Azhar Assiut Uniuersity.

Egypt

AADJ, Vol. 2, No. 2, October (2019) - PP. 125:133

ISSn 2682-2822

\section{Evaluation of Topical Ozone Gel on Postoperative Sequelae Following Impacted Lower Third Molar Surgery}

\author{
Sherif S. Alkholy ${ }^{* 1}$, Mahmoud A. Abdallah"1, Abdel Aziz B. Abdullah²
}

Codex : 15/1910

Aadj@azhar.edu.eg

\section{KEYWORDS}

Ozone gel,

impacted lower third molar surgery,

VAS, check dimensions,

pain.

1. Department of Oral and Maxillofacial Surgery, Faculty of Dental Medicine, Al-Azhar University,(Cairo, Boys), Egypt.

2. Department of Oral and Maxillofacial Surgery, Faculty of Dental medicine, Al-Azhar University, Assiut, Egypt.

* Corresponding Author e-mail: shreefsaad.p.9@azhar.edu.eg

\begin{abstract}
Aim: It was to evaluate the use of topical ozone gel on post-operative sequelae following impacted lower third molar surgery. Subjects and Methods: the current study included 30 patients divided randomly into equal three groups. Clinical examination included assessment of maximal mouth opening and cheek dimensions preoperatively. Panoramic x-ray was used for evaluation of the location and configuration of impacted lower third molar, surrounding bone, mandibular canal and adjacent tooth. The maximal mouth opening and check dimensions were remeasured postoperatively at days 2 , 5 and 7. All readings were recorded and analyzed statistically. Results: Results showed statistical significance regarding pain while there was no statistical significance regarding mouth opening and swelling. Conclusion: Topical ozone gel is useful for the reduction of postoperative pain after lower third molar surgery.
\end{abstract}

\section{INTRODUCTION}

Third molar surgery is one of the most common procedures performed in oral and maxillofacial surgery field. Nevertheless, this procedure requires accurate planning and surgical skills. With surgical procedures in general, complications can always arise. The reported frequencies of complications after third molar removal are reported between 2.6 percent and 30.9 percent. The spectrum of complications ranges from minor expected sequelae of post-operative pain and swelling to permanent nerve damage, mandibular fractures, and life threatening infections ${ }^{1,2}$.

The most common complications of third molar surgery are pain, swelling, and trismus. They are attributed to inflammation due to tissue injury or infection. Attempts to overcome these complications and achieving good post-operative recovery have been done using systemic medication like antibiotics, glucocorticoids and analgesics ${ }^{2}$. Recently ozone therapy has been used in medical and dental practice 
with promising results ${ }^{3}$ subjects treated with topical minocycline during surgery, and subjects enrolled in a nonconcurrent comparison group who had received neither topical minocycline nor directed cryotherapy. Third molar surgery was performed in all cases by trained surgeons using the same protocol. An exact Kruskal-Wallis test was used to compare the distributions of the worst and average pain scores and a Fisher exact test to compare verbal responses from Gracely pain scales among the 3 groups for postsurgical days (PSDs.

Ozone $\left(\mathrm{O}_{3}\right)$ is an allotropic form of oxygen, primarily known for its ecological properties, industrial application and therapeutic effects. It is a triatomic molecule with three oxygen atoms and molecular weight of $47.98 \mathrm{~g} / \mathrm{mol}^{4}$. Thermodynamically, this molecule is a highly unstable compound that decomposes to pure oxygen with a short half-life in particular temperature and pressure conditions ${ }^{5}$.

Ozone modulates cellular and humoral immunity by activating macrophages and stimulating synthesis of biologically active substances respectively ${ }^{6}$. This remarkably reduces inflammation and improves wound healing. The antimicrobial action of ozone extends over a wide spectrum; bactericidal, veridical, and fungicidal ${ }^{7}$.

The use of ozone in oral and maxillofacial surgery has been limited; articles regarding the use of ozone after impacted lower third molar surgery are scarce. Accordingly this study was designed to answer the following clinical query, does topical ozone therapy improve post-operative healing and reduce the complications after impacted lower third molar surgery.

\section{PATIENT AND METHODS}

This Randomized Controlled Clinical Trial study was conducted on thirty adult patients of both genders. All patients had impacted lower third molars indicated for surgical removal. Appropriate ethical clearance was granted from the institution in which the study was carried out; also an informed consent was obtained from all patients. The patients were selected from the Out Patient Clinic of the Oral \& Maxillofacial Surgery Department, Faculty of Dentistry, Al-Azhar University.

Patients were randomly divided into three groups; group I, II and III:

In group I: Patients received topical ozone (Pur $\mathrm{O}_{3}$ ) application after surgery.

In group II: Patients received systemic antibiotics (amoxicillin $500 \mathrm{mg}$ ) before and after surgery.

In group III: patients received neither ozone nor antibiotics and served as control.

\section{A -Preoperative phase}

A complete clinical history was taken at the first visit, with collection of the following information: patient age and sex; identification of the molar to be removed and reason for removal; level of impaction (totally covered by bone, totally covered by soft tissue, partially covered by soft tissue, or completely erupted); and the presence of associated symptoms and/or diseases. The maximal mouth opening was assessed and measured with a simple caliper. This was considered as the preoperative base line measurement of the maximal mouth opening. Cheek dimensions were measured in millimeters with a flexible measuring tape using the following 3 reference planes $^{6}$ (fig. 1):

1. AC- the most posterior point on the tragus to the lateral point on the corner of mouth.

2. AD- the most posterior point on the tragus to the soft tissue pogonion.

3. BE- the lateral canthus of the eye to the most inferior point on the angle of the mandible.

The sum of $\mathrm{AC}+\mathrm{AD}+\mathrm{BE}$ was considered as the preoperative base line cheek dimension value. 


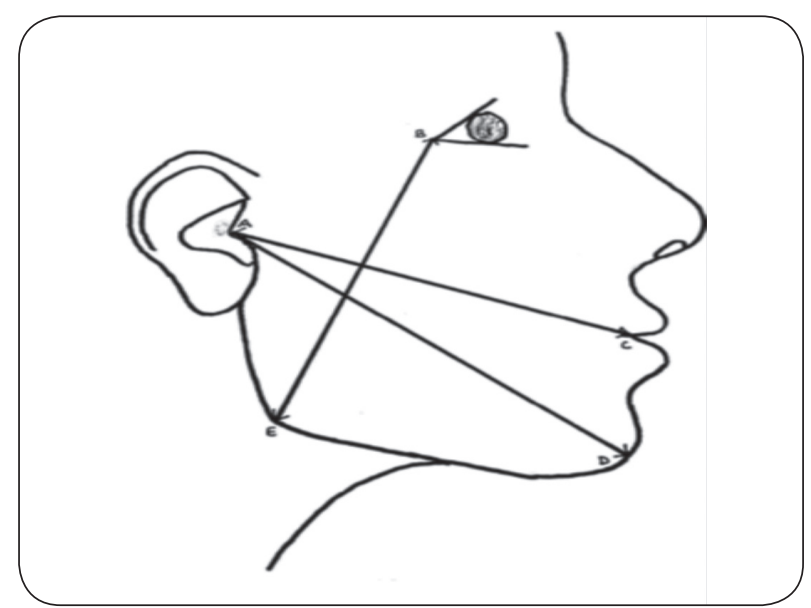

Fig. (1) Tape-measuring method

\section{B -Operative phase}

For all groups, a standardized surgical procedure was adopted; surgery was performed under local anesthesia articaine $4 \%$ hydrochloride with epinephrine 1:100.000 (Artinibsa, Inibsa Dental S.L.U, Spain) using inferior alveolar, lingual and buccal nerves block. A three sided mucoperiosteal flap was utilized. Using blade number 15 , the incision was started just to the lingual side of the external oblique ridge of the ramus of the mandible at a distance of about $3 / 4$ inch distally from the lower $2^{\text {nd }}$ molar. Then, it was directed anteriorly until it contacted the midpoint of the distal of the lower $2^{\text {nd }}$ molar. The incision was then continued buccally to just before the interproximal space between the $1^{\text {st }}$ and $2^{\text {nd }}$ molar teeth. From there it was extended down toward the mucobuccal fold at a 45 degree angle. The mucoperiosteal flap was raised using periosteal elevator.

Osteotomy was performed using a low speed handpiece with rose head bur with abundant irrigation. Tooth sectioning was performed using a highspeed handpiece with fissure bur. Tooth was delivered and the bone edges were refined. After complete removal of the tooth, the socket was inspected, irrigated copiously, and the flap was sutured back. The mean surgical time was recorded from the time of incision to the last suture for wound closure in minutes.

\section{C- Postoperative phase}

Post extraction wound management varied between the three groups. Group 1 received topical ozone as an application filling the entire socket and as a smear on the vertical limb of the incision after careful isolation of the surgical site. The patients were instructed to apply topical ozone as a smear layer on the edges of the flap, using a scoop for 2 minutes, 3 times a day, for 5 days. Group II received plain gauze pack and instructed to continue systemic antibiotics 3 times a day for 5 days. Group III received only plain gauze pack (fig.2).

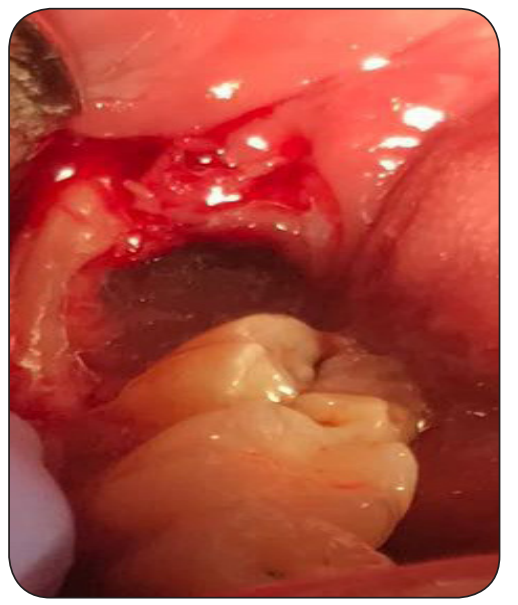

Fig. (1) Filling the entire socket with ozone gel

Patients of all groups were instructed to bite down gently but firmly on the gauze pack that have been placed over the surgical area, making sure it remains in place almost for an hour. After this time, the gauze pad should be removed and discarded.

Patients were instructed that if bleeding persists, to repeat the process. Rinsing or swishing was avoided for 24 hours after extraction. Smoking was stopped following surgery. Patients were asked to place the ice packs on the sides of the face where the surgery was performed to help reduce swelling. After 24 hours' patients began gentle rinsing with a saltwater solution $(1 / 2$ teaspoon salt $+1 / 2$ teaspoon 
soda +8 ounces' warm water). They were instructed to take soft foods for the first two days. Patients of all groups were prescribed Ibuprofen $600 \mathrm{mg}$ to be taken whenever needed (every 8 hrs. maximum 3 tablets per day). Sutures were removed on the $7^{\text {th }}$ postoperative day.

\section{D- Follow up phase}

\section{Clinical evaluation}

Patients were recalled postoperatively on days 2, 5 and 7 for clinical assessment. The wound was thoroughly inspected for signs of infection, dehiscence or dry socket formation. Any disturbance of healing was recorded. Diagnosis of dry socket was established by the clinical symptoms (severe pain accompanied with foul taste, or halitosis and denuded socket) that may occur one to three days after surgery.

- The maximal mouth opening was measured in millimeters using calipers as done before surgical intervention. The postoperative readings were collected to be compared to the preoperative reading.

- Cheek dimension was measured in millimeters with a flexible measuring tape as done before surgical intervention. The postoperative readings were collected to be compared to the preoperative reading.

- Post-operative pain was assessed using a numeric pain rating scale modified visual analog scale $^{6}$. On the VAS, the leftmost end represented the absence of pain (score 0 ) and the rightmost end indicated the most severe pain (score 10). The severity of pain was rated by patients. Rate of 0 means no pain, 1-3 mild pain, 4-7 moderate pain and 8- 10 severe pain.

\section{Statistical analysis:}

Data were coded and entered using the statistical package SPSS (Statistical Package for the Social
Sciences) version 25. Comparisons between quantitative variables were done using the non-parametric Kruskal-Wallis and Mann-Whitney tests ${ }^{8}$. P-values less than 0.05 were considered as statistically significant. For comparison of serial measurements within each group repeated measures ANOVA was used $^{10}$

\section{RESULTS}

The current study included 30 patients (11 females \& 19 males) with an age between 21 and 40 years. All patients presented with impacted lower third molars indicated for surgical removal according to the predetermined inclusion and exclusion criteria. They were divided randomly into three equal groups, 10 patients each. In group I, patients received topical ozone as an application filling the entire socket after surgery. In group II, patients received systemic antibiotics. In group III, patients received neither ozone nor antibiotics. In all groups flaps were repositioned and sutured using 3-0 braided black silk. Thirty impacted lower third molar tooth extractions were performed without any complication. The mean operation time from the first incision to the last suture was $25.20 \pm 3.29,25.40 \pm 3.24$ and $25.50 \pm 2.92$ in groups I, II and III respectively no statistical difference was found between groups. In all groups, healing was uneventful. Dry socket occurred in one patient in group III. Dry socket has been healed satisfactory by alveogel dressing. Paresthesia, bleeding, or altered nerve sensation were not observed in any patient postoperatively. Neither infection nor dehiscence was recorded. Postoperative limitation of mouth opening occurred in all groups. Gradual improvement of mouth opening was seen in most patients within the first week. Patients of all groups have developed edema following surgical intervention.

The edema started by the end of the day of surgery and reached its peak within 48 hours. It was subsided after 5 to 7 days of the procedure. Postoperative pain was experienced by patients 
of all groups. Pain intensity reached its maximum level at the second postoperative day. The degree of pain that the patients experienced in group I was significantly lower than that of the other groups. The number of analgesic tablets taken was recorded and it was found that significantly fewer analgesics were taken for the ozone group when compared to the other groups.

\section{Descriptive statistics of mouth opening:}

The difference between groups was statistically non-significant as indicated by Kruskal-Wallis test preoperatively and throughout the whole observation periods at days 2, 5 and 7 as shown in table (1).

Table (1) Mean $\pm S D$ and $P$ values of maximal mouth opening (in $\mathrm{mm}$ ) for all groups along the different observation periods.

\begin{tabular}{|l|c|c|c|c|}
\hline & Preoperative & Day 2 & Day 5 & Day 7 \\
\hline Group I & $43.5 \pm 3.27$ & $35.9 \pm 4.86$ & $39.8 \pm 4.24$ & $42.4 \pm 4.01$ \\
\hline Group II & $43.8 \pm 2.82$ & $30.8 \pm 6.32$ & $35.9 \pm 4.95$ & $38.8 \pm 3.33$ \\
\hline Group III & $44.9 \pm 2.56$ & $31.4 \pm 3.84$ & $36.4 \pm 5.21$ & $37.6 \pm 4.84$ \\
\hline P Value & $\mathbf{0 . 3 9}$ & $\mathbf{0 . 0 9 3}$ & $\mathbf{0 . 1 8 2}$ & $\mathbf{0 . 1 0 9}$ \\
\hline
\end{tabular}

\section{Descriptive statistics of cheek dimension (swelling):}

The difference between groups was statistically non-significant as indicated by Kruskal-Wallis test preoperatively and at days 2 and 7 , while at the $5^{\text {th }}$ postoperative day the difference between groups was statistically significant as shown in table (2) and fig. (3). Mann-Whitney test corrected by Benferroni showed statistically significant difference between group I and group III. The cheek dimension mean values differed at the $5^{\text {th }}$ postoperative day, being significantly lower in group I than in group $3(\mathrm{p}=0.016)$. No significant difference was found between group 1 and group 2 as well as between group II and group III.
Table (2) Mean $\pm S D$ and $P$ values of cheek dimension (in mm) for all groups along the different observation periods

\begin{tabular}{|l|c|c|c|c|}
\hline & Preoperative & Day 2 & Day 5 & Day 7 \\
\hline Group I & $289 \pm 5.31$ & $295.4 \pm 10.98$ & $294.9 \pm 10.48$ & $292.1 \pm 6.14$ \\
\hline Group II & $289.8 \pm 4.61$ & $301.8 \pm 8.61$ & $298.5 \pm 7.03$ & $294 \pm 5.31$ \\
\hline Group III & $292 \pm 3.37$ & $308.1 \pm 10.99$ & $306.4 \pm 9.34$ & $298 \pm 4.37$ \\
\hline P Value & 0.224 & 0.063 & $0.048^{*}$ & 0.061 \\
\hline
\end{tabular}

*=Significant

\section{Descriptive statistics of pain:}

The difference between groups was statistically significant as indicated by Kruskal-Wallis test at the $2^{\text {nd }}$ postoperative day, while at days 5 and 7 postoperatively the difference between groups was statistically non-significant as shown in table (3) and fig. (4). Mann-Whitney test corrected by Benferroni showed statistically significant difference between group I and group III. The mean pain score values differed between two groups at the 2 nd postoperative day, being significantly lower in group I than in group 3(p=0.031). No significant difference was found between group I and group II as well as between group II and group III.

Table (3) Mean $\pm S D$ and $P$ values of pain scores (VAS) in all groups along the different observation periods.

\begin{tabular}{|c|c|c|c|}
\hline & 2nd Day & 5th Day & 7th Day \\
\hline Group I & $3.1 \pm 2.18$ & $2.6 \pm 1.43$ & $0.7 \pm 0.95$ \\
\hline Group II & $4.2 \pm 2.2$ & $2.5 \pm 1.51$ & $1.2 \pm 1.23$ \\
\hline Group III & $6 \pm 2.45$ & $3.7 \pm 1.77$ & $1.5 \pm 1.51$ \\
\hline P Value & $0.037 *$ & 0.357 & 0.409 \\
\hline
\end{tabular}

*=Significant 


\section{DISCUSSION}

Surgical extraction of the third molars is widely carried out in dental practice. The surgical procedure causes damage to the tissue which leads to release of potassium, serotonins and histamines from the damaged cells, and the release of bradykinin from the damaged blood vessels. This causes the activation of nocioceptors, change of the tissue coloration and edema as a response of the tissue. Bradykinin causes release of prostaglandin and activation of nocioceptors. The end result is the development of symptoms like pain, swelling, and restricted mouth opening $^{1,11,12}$.

Studies have shown that pain reaches maximum intensity at $3-5 \mathrm{~h}$ after surgery, continuing for 2-3 days, and gradually diminishing until the 7 th day ${ }^{1}$. Postoperative swelling reaches peak intensity within 12-48 hrs and resolving between the 5th and 7th days postoperatively. During the first 4 to 7 days after the surgical treatment, the negative impact to the quality of life can be expected ${ }^{1,2}$. The effect of impacted lower third molar surgery on quality of life has been reported to show a threefold increase in patients who experience pain, extra oral swelling, and trismus, alone or in combination, compared to those who are asymptomatic ${ }^{11,12}$. After that, it is common to observe the decrease of the expected postoperative complications resulting in a significant improvement of the quality of life ${ }^{13}$.

Accordingly, many clinicians ${ }^{13-16}$ have emphasized the necessity for better control of pain, swelling, and trismus in patients who undergo third molar surgery. The use of local or systemic corticosteroids and nonsteroidal anti-inflammatory drugs is often recommended. However, the majority of these may manifest side effects such as a tendency to systemic bleeding, gastrointestinal irritation, and allergic reactions. These observations justify efforts to find a new method of postoperative complications control that does not induce side effects. Ozone therapy in dentistry is gaining a place in everyday dental practice and is used in almost all dental applications.
Ozone can react with blood components (erythrocytes, leukocytes, platelets, endothelial cells, and the vascular system) and positively affect oxygen metabolism, cell energy, the immunomodulatory effect, antioxidant defense system, and microcirculation in the tissues ${ }^{17,18}$. Accordingly, it has antimicrobial, disinfectant, and wound healing properties. Therefore, the recommended indications for ozone treatment are enhancing epithelial wound healing in cases such as ulcerations and herpetic lesions. In dentoalveolar surgery, ozone may be useful to promote hemostasis, enhance the local oxygen supply, enhance epithelial wound healing, and inhibit bacterial growth ${ }^{18-21}$.

This study was designed to evaluate the effect of ozone gel on local signs of inflammation, including trismus, facial swelling, and pain after impacted third molar surgery compared to antibiotic therapy. Impacted lower third molar tooth was selected as a model to perform the study. Impacted mandibular third molar is widely used as a model for evaluation of the medicaments, as almost always minor postoperative complications may be expected ${ }^{6}$.

The present study showed a nonsignificant effect of ozone on the trismus as can be read from the results. Actually it was found that the highest maximal mouth opening mean value recorded for group 1 followed by group II while the lowest mean value recorded for group III. However, the difference between groups was statistically non-significant. Although the difference between groups was statistically nonsignificant, patients of group 1 almost returned to the preoperative mouth opening value at the 7th postoperative day. This was not the case in group II and group III. The explanation of ozone group faster return to normal mouth opening than other groups is attributed to better wound healing facilitated by the biosynthetic and analgesic properties of ozone $e^{6,22}$.

Regarding trismus, results of the present study is in accordance with Kazancioglu et al ${ }^{23}$ who found that the ozone has no effect on trismus. On the other 
hand, Sivalingam et al., ${ }^{6}$ Shokry et al ${ }^{18}$ and Erdemci et $\mathrm{al}^{24}$. Sivalingam et al., ${ }^{6}$ found that topical ozone therapy provided excellent patient comfort following surgical removal of impacted mandibular third molars by effectively reducing the postoperative swelling, pain and in turn trismus. Shokry et $\mathrm{al}^{18}$ found that the ozone therapy improved the bone healing of the socket in addition to reduce the postoperative symptom of trismus. Erdemci et al ${ }^{24}$ investigated the effects of systemic and topical ozone applications on alveolar bone healing following tooth extraction. They found that the postoperative long-term systemic ozone application could accelerate alveolar bone healing following extraction. They attributed the positive effect of ozone on mouth opening to better wound healing.

As regard to swelling, the current study showed a minimal effect of the ozone treated group than that in other groups. It was clear from the results that the ozone therapy group has lower mean value of facial edema all over the observation periods than the other groups. However, this was statistically nonsignificant. The only significant difference between groups was found at the $5^{\text {th }}$ postoperative day between the ozone treated group and the control group. This may be due to the application of ozone after extraction for five days. Ozone modulates cellular and humoral immunity by activating macrophages and stimulating synthesis of biologically active substances respectively. This remarkably reduces inflammation and improves wound healing.

With reference to swelling, results of the current study is in agreement with Kazancioglu et al ${ }^{23}$ who found that the ozone has no effect on facial swelling and in disagreement with Sivalingam et $\mathrm{al}^{6}$ and Shokry et $\mathrm{al}^{18}$. Sivalingam et $\mathrm{al}^{6}$ reported that the patients in the ozone treated group revealed lesser swelling in relation to the control. Shokry et al ${ }^{18}$ showed that facial swelling had reduced and resolved more rapidly in the study side that received ozone gel than the control side.
Patients of ozone group showed the least mean VAS value at the $2^{\text {nd }}$ postoperative day than group 2 and group 3 . The difference was statistically significant. No difference was found between groups on the $5^{\text {th }}$ and $7^{\text {th }}$ postoperative days. The explanation is that the protective layer of ozone gel over the surgical site in the initial postoperative phase possibly prevents wound contamination and also covers the exposed nerve endings, thereby significantly reducing pain when compared to the antibiotic and control groups.

\section{CONCLUSIONS}

This study concluded that the use of ozone gel is useful for the reduction of postoperative pain and the need for analgesics after lower third molar surgery. The use of ozone gel has no effect on postoperative trismus and swelling after lower third molar surgery. The use of antibiotic therapy did not demonstrate efficacy in prophylaxis for postoperative inflammatory complications (trismus, swelling and pain) after lower third molar surgery.

\section{REFERENCES}

1. Green R, Pynn B, Brauer H. Complications During and After Surgical Removal of Third Molars. Oral Heal Gr . 2013;1:1-11.

2. Deliverska E, Petkova M. Complications After Extraction of Impacted Third Molars - Literature Review. J IMAB. 2016;22(3):1202-11.

3. Gelesko S, Long L, Faulk J, Phillips C, Dicus C, White RP. Cryotherapy and topical minocycline as adjunctive measures to control pain after third molar surgery: An exploratory study. J Oral Maxillofac Surg . 2011;69(11):324-32.

4. Mohammadi Z, Shalavi S, Soltani M, Asgary S. A review of the properties and applications of ozone in endodontics: an update. Iran Endod J . 2013;8(2):40-3.

5. Saini R. Ozone therapy in dentistry: A strategic review. J Nat Sci Biol Med . 2011;2(2):151-3.

6. Sivalingam VP, Panneerselvam E, Raja K, Gopi G. Does topical ozone therapy improve patient comfort after 
surgical removal of impacted mandibular third molar? A randomized controlled trial. J Oral Maxillofac Surg . 2017;75(1):51-9.

7. Aizenshtein E, Pinchasov Y, Morag E, Leitner G, Shpanir Y, Reimond D, et al. Immunological complex for enhancement of innate immune response in passive vaccination. Vaccine . 2013;31(4):626-31.

8. Chan YH. Biostatistics 102: quantitative data-parametric \& non-parametric tests. blood Press. 2003;140(24.08):0-79.

9. Chan YH. Biostatistics 103: qualitative data-tests of independence. Singapore Med J . 2003;44(10):498-503.

10. Chan YH. Biostatistics 301. Repeated measurement analysis. Singapore Med J . 2004;45:354-69.

11. Deliverska E, Petkova M. Complications After Extraction of Impacted Third Molars - Literature Review. J IMAB Annu Proceeding Scientific Pap. 2016;22(3):1202-11.

12. Oliveira S, Melo A, Agnelli R, Maia P, Kalil S, Porta $K$. Effect of low-level laser therapy on the post-surgical inflammatory process after third molar removal: Study protocol for a double-blind randomized controlled trial. Trials. 2013;14(1):373-9.

13. Rodanant P, Wattanajitseree K, Shrestha B, Wongsirichat N. Pain and quality of life related to suture removal after 3 or 7 days at the extraction sites of impacted lower third molars. J Dent Anesth Pain Med. 2016;16(2):131-6.

14. Isola G, Alibrandi A, Pedulla E, Grassia V, Ferlito $\mathrm{S}$, Perillo L. et al. Analysis of the Effectiveness of Lornoxicam and Flurbiprofen on Management of Pain and Sequelae Following Third Molar Surgery: A Randomized, Controlled, Clinical Trial. . J Clin Med. 2019;8(3):325-37.

15. Dhanavelu P, Shanmugapriyan, Ebenezer V, Balakrishnan and Elumalaim. Deaxmethasone for third molar surgery A review. Int J Pharm Bio Sci. 2013; 4(4):9-13.
16. Poveda R, Bagan J, Sanchis J, Carbonell E. Antibiotic use in dental practice. A review. Med Oral Patol Oral Cir Bucal. 2007;12(3):186-92.

17. Domb W. Ozone therapy in dentistry: A brief review for physicians. Interv Neuroradiol. 2014;20(5):632-6.

18. Shokry M, Alshaimaa S. Effect of xenograft-ozonated gel mixture on alveolar bone healing following removal of impacted third molar: A randomized controlled clinical trial. Egypt Dent J . 2016;62(4):4749-57.

19. Gupta G, Mansi B. Ozone therapy in periodontics. J Med Life. 2012;5(1):59-67.

20. Reedy S A, Reddy N, Dinapadu S, Reddy M, Pasari S. Role of ozone therapy in minimal intervention dentistry and endodontics - a review. J Int oral Heal $\mathrm{JIOH}$. 2013;5(3):102-8.

21. Patel PV, Gujjari SK. The Morphometrical and Histopathological Changes which were observed after Topical Ozone Therapy on an Exophytic Fibrous Gingival Lesion: A Case Report, J Clin Diagn Res. 2013;7(6);123943.

22. Balakrishnan G, Narendar R, Kavin T, Venkataraman $\mathrm{S}$, and Gokulanathan S. Incidence of Trismus in Transalveolar Extraction of Lower Third Molar J Pharm Bioallied Sci. 2017; 9(1): 222-27.

23. Kazancioglu HO, Ezirganli S, Demirtas N. Comparison of the influence of ozone and laser therapies on pain, swelling, and trismus following impacted third-molar surgery. Lasers Med Sci. 2014;29(4):1313-9.

24. Erdemci F, Gunaydin Y, Sencimen M, Bassorgun I, Ozler M, Oter S, et al. Histomorphometric evaluation of the effect of systemic and topical ozone on alveolar bone healing following tooth extraction in rats. Int J Oral Maxillofac Surg. 2014;43(6):777-83. 


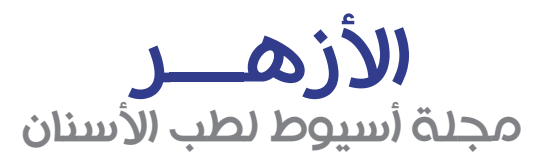

النشر الرسمي لكلية طب الأسنان جامعة الأزهر أسيوط النمر لكمر

\title{
تقييم استخدام هلام الأوزون الموضعي علم تبعات ما بعد المون جراحة ضرس العقل السفلي المون المدفون
}

\author{
شريف سعد الخولى *1, محمود عبدالله شحاته1, عبدالعزيز بيومى عبدالله2 \\ 1 قسم جراحسة الفم والوجها وافكين, كليـة طب الاسنان، جامعة الازهر، (القاهره ربنين)، مصر \\ 2 قسـم جراحة الفم والوجهـ وافكين، كلية طب الاسـنان، جامعة الازهر، اسيوط، مصر \\ SHREEFSAAD.P.9 @AZHAR.EDU.EG البريد الالكترونى ** *
}

الملخص :

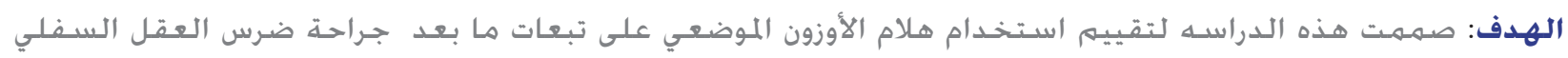
المدفون.

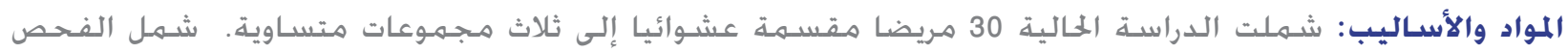

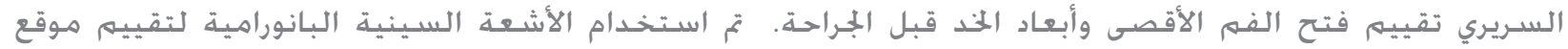

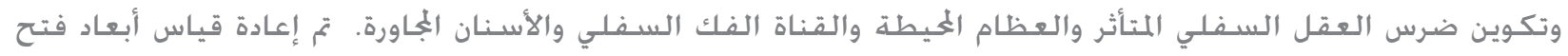

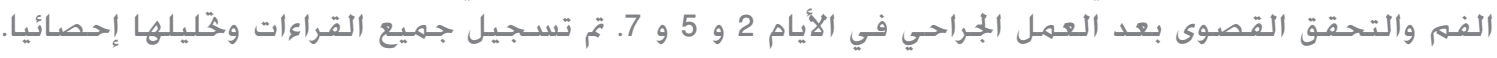

النتائج: أظهرت النتائج دلالة إحصائية فيما يتعلق بالألم بينما لهم يكن هناك دلالة إحصائية فيما يتعلق بفتح الفهم وتورهـ. الخلاصة: هلام الأوزون الموضعي مفيد لتخفيف آلام ها بعد جراحة ضرس العقل السفلي المدفون الكلمات المفتاحيه: هلام الاوزون , جراحة ضرس العقل المدفون , مقياس فاز, ابعاد الخذد , الالم 